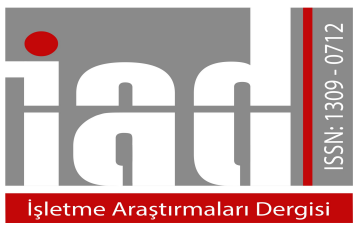

Journal Of

Business Research

Turk

www.isarder.org

\title{
Marka Güveni Marka Sadakati ve Marka Tercihi Arasındaki İlişkinin İncelenmesi: Kurtasiye Sektörü Uygulaması \\ Analysis of Associations Between Brand Trust Brand Loyalty and Brand \\ Preference: Stationery Industry Application
}

\author{
Vahap ÖNEN \\ İstanbul Okan Üniversitesi \\ Uygulamalı Bilimler Fakültesi \\ Sivil Havacılık Yönetimi, İstanbul, Türkiye \\ orcid.org/0000-0001-8592-9430 \\ vahap.onen@okan.edu.tr
}

\begin{abstract}
Özet
Markaya olan güvenin gerek marka sadakati açısından gerekse de marka tercihi açısından olması gereken daha önemli bir bileşen olduğu öngörülmekle birlikte literatürde bu üç marka bileșeni arasındaki ilișkiyi inceleyen pek fazla çalıșma bulunmamaktadır. $\mathrm{Bu}$ nedenle çalışmada üç marka bileşeni arasındaki etkileşimin incelenmesi amaç edinilmiştir. Araştırma kırtasiye boya kalemi sektöründe yüz yüze anket yöntemi uygulanarak gerçekleştirilmiştir. Çalışmada marka güveni ölçeği için Delgado-Ballester'ın, marka sadakati ölçeği için Özdemir ve Koçak'ın, marka tercihi içinse Chang ve Liu'nin geliştirdiği ölçek kullanılmıştır. İlgili marka bileşenleri arasındaki etkiyi belirlemek üzere araştırma yöntemi olarak doğrusal regresyon modeli kullanılmıştır. Ölçekler kullanıma hazır hale getirilmesi için faktör ve güvenirlik analizlerine tabi tutulmuştur. Yapılan analizde müşterilerin, üç firmanın da marka güveni, marka sadakati ve marka tercihi düzeylerini yeterli görmediği ve bunların geliştirmesi gerektiği belirlenmiştir. Regresyon analizi neticesinde ise; marka güveni ile marka sadakati arasında anlamlı ve pozitif yönde bir ilişki olduğu, marka güveni ile marka tercihi arasında yüksek seviyede pozitif, anlamlı bir etki olduğu ve en son olarak da marka tercihi ile marka sadakati arasında anlamlı ve pozitif yönde bir etki olduğu ortaya çıkmıştır. Sonuç olarak; marka güveni gerek marka sadakatini gerekse de marka tercihini anlamlı ve olumlu yönde etkilediği ayrıca; marka tercihinin de marka sadakatini istatiksel olarak anlamlı ve pozitif yönde etkilediği, marka güveninin marka sadakati ve marka tercihinin sağlanmasına yönelik önemli ve ortak bir bileşen olduğu tespit edilerek konuyla ilgili hipotezler kabul edilmiştir.
\end{abstract}

Anahtar Kelimeler: Marka Sadakati Marka Güveni Marka Tercihi Kırtasiye Sektörü 


\begin{abstract}
While brand trust is expected to be a more important component in terms of brand loyalty and brand preference, there are not many studies in the literature that examine the relationship between these three brand components. For this reason, the purpose of this study is to measure the associaitions among the three brand components. The study was performed in the stationery paint sector and face to face survey method was applied. In the study, Delgado-Ballester's brand trust scale, Özdemir and Koçak's brand loyalty scale and Chang and Liu's brand preference scale were used. A linear regression model was used as as a research method to determine the associations between the three brand components. Scales were subjected to factor and reliability analyzes in order to make the scales ready for use. It has been found that each company's brand trust, brand loyalty and brand preference levels are not satisfactory and they shoud be improved according to customers' evaluation. As a result of regressions analysis, it has been determined a significant and positive association between brand trust and brand loyalty as a first, secondly significant and positive association found between brand trust and brand preference, and thirdly significant and positive association found between brand preference and brand loyalty. To conclude with it can be sait that brand trust affects both brand loyalty and brand choice in a meaningful and positive way and brand preference affects brand loyalty in a statistically significant and positive way and brand trust is the partner component for formation of brand loyalty and brand preference therefore related hypothesis are accepted.
\end{abstract}

Keywords: Brand Loyalty Brand Trust Brand Preferenece Stationery Industry

\title{
1. Giriş
}

Günümüz yoğun rekabet ortamından kaçınmanın önemli bir yolu ürün ve hizmetlerin markalaştırılmasından geçmektedir. Başarılı markaların özellikleri incelendiğinde markaya olan güvenin bunda büyük bir önemi olduğu söylenebilir. Eğer tüketiciler bir markaya karşı güçlü güven duyarlarsa o zaman mal ve hizmetlerin yeniden satışı, rakip firmalara geçişin önlenmesi, markaya yönelik olumsuzlukların göz ardı edilmesi mümkün olabilmektedir. Bu durum kırtasiye sektörü gibi düşük kar marjı ile çalışan ve birbirlerini kolayca takip edilen sektörlerde daha da önemli hale gelmektedir. Markalaşma yolunda öncelikli olarak markaya olan güvenin sağlanması gerekmektedir. Literatürde yapılan birçok çalışmada, örneğin (Eren ve Erge, 2012) "Marka Güveni, Marka Memnuniyeti Ve Müşteri Değerinin Tüketicilerin Marka Sadakati Üzerine Etkisi" makalesinde olduğu gibi marka güveninin marka sadakatini destekleyen çeşitli görüşler yer almaktadır. Buna ilaveten marka tercihinin bir ürün ya da hizmetin seçilmesine yönelik bir davranışın sonucunda meydana geldiği söylenebilir. Ancak marka tercihinin de sağlanabilmesi için markaya olan güvenin sağlanması gerektiği düşünülmektedir. Bu açıdan marka güveni hem markaya olan sadakatin hem de markaya olan tercihin oluşmasında etki eden önemli bir bileşen olduğu öngörülmektedir. Yapılan çalışmalarda örneğin (Gürbüz ve Doğan, 2013) "Tüketicilerin Markaya Duyduğu Güven ve Marka Bağlılığı İlişkisi” makalesinde genelde marka güveninin marka bağl1lı̆g üzerinde de etkili olduğu ve bu etkinin hizmet sektöründe daha fazla olduğu belirlenmiştir. Literatür değerlendirildiğinde yapılan çalışmalarda marka güveninin marka ve müşteri arasında değerli bir alışveriş ilişkisi yarattığı ve bu ilişkinin devamlılığını sağlayarak marka bağlılı̆̆ı oluşumunda öncü olduğu ifade edilmiştir (Morgan ve Hunt, 1994, s.30). (Harris ve Goode, 2004) yaptıkları çalışmada 
tekrar satın alma davranışlarında da yine marka güveninin etkili olduğuna değinmişlerdir. Ancak literatürde marka güveni, marka bağl1lı̆̆ ve marka tercihi ilişkisinin birlikte değerlendirildiği çalışmalar pek görülmemiştir. $\mathrm{Bu}$ nedenle her üç marka bileşeni arasındaki ilişkinin ortaya konulması açsından bu çalışmanın önemli bir katkı sağlayacağı düşünülmektedir.

\section{Literatür Taraması}

Sadakat, müşterinin bir firma ya da marka ile olan ilişkisini devam ettirmek istemesidir (Cyr vd., 2006). Diğer bir ifadeyle, sadakat, müşteri taahhüdüdür (Evanschitzky vd, 2006). Tüketicinin ürün veya hizmetle ilgili bireysel değerlendirme yapmalarında ve karar aşaması sürecinde marka sadakati önemli bir rol üstlenmektedir (Yoon ve Kim, 2000, s.120). Müşteri sadakati, bir müşterinin hizmete, ürüne, markaya ya da işletmeye olan tutumu olarak da tanımlamaktadır. Marka sadakati yalnızca aynı ürünü satın alma eğilimi olmayıp, psikolojik olarak bağlılık ve markaya karşı tutumu da kapsayan bir kavramdır. Marka sadakati olan müşteriler yalnızca markayı satın almazlar, diğer markalardan gelen daha iyi, daha cazip teklifleri de reddederler. Miller ve Grazer (2003), marka sadakatini tekrar eden satın almalar, fiyatın tölere edilebilmesi ve başkalarına tavsiye edilmesi olarak ifade etmektedir. Marka sadakati yüksek olan müşteriler markayı sürekli satın alırlar ve markaya olan bağlılıkları oldukça yüksektir. Marka sadakati bu bağlamda rekabetçi stratejilere karşı da dirençli bir müşteri kitlesi oluşturabilmektedir (Devrani, 2009, s. 408). Marka sadakati, (Dick ve Basu, 1994, s.99) tarafından bir bireyin göreceli tavrı ile devamlı müşteri olma arasındaki ilişkinin gücü olarak tanımlanmıştır. Oliver'a göre (1999, s. 35-36) marka sadakati bilişsel sadakat, duygusal sadakat, çabasal sadakat ve eylemsel sadakat boyutlarından oluşmaktadır. Bu nedenle tutumsal sadakat ise son derece önemlidir zira bu tür müşteriler ürünleri sürekli kulnmazsa bile başkalarına tavsiye etme potansiyeline sahiptirler bu da daha fazla ürün satışına yol açacaktır. Başkalarına tavsiye edilen bir ürünün ise doğal olarak marak değeri yükselmektedir. Sadakat, bir ürün ya da hizmete müşteri olma sıklığı, sürekli olarak aynı mal ve hizmeti ya da firmayı tercih etmek olarak tanımlanmıştır (Zeithaml vd., 1996). Davranışsal yönden sağlanacak sadakat ürünün pazar payının artmasına yol açacaktır. Tüm bunların sonucunda sadakatin tutumsal ve davranışsal yönden sağlanması marka güvenirliliğini olumlu yönde artmasına yol açacaktır. Chaudhuri ve Holbrook (2001) yaptıkları çalışmada marka sadakatinin ve marka etkisinin davranışsal ve tutumsal sadakate birlikte etkisi olduğunu ortaya çıkarmıştır.

Güven kavramı pek çok disiplinde tartışılan ve açıklanmaya çalışılan bir kavram olarak çıkmaktadır. Bireylerin ekonomik faaliyetlerinin yalnızca ekonomik değişkenlerle değil aynı zamanda sosyolojik ve psikolojik unsurların da dikkate alınmasıyla incelenmesi gerektiğini savunan "davranışsal ekonomi” alanındaki gelişmeler güvenin etkisinin de ekonomik çalışmalarda incelenmesi gereğini yansıtmaktadır. Çünkü güven bireylerin ve toplumların her türlü kararlarında en temel unsurlardan biri olarak kabul edilmektedir (Kara, 2009). İşletmeye duyulacak güven daha kapsayıcı bir özellik göstermekle birlikte, markaya duyulan güven de işletmeye olumlu düşünceler duyulmasını beraberinde getirecektir. Güven, bir markayı satın alma niyetinden önce o markaya inanmadır. Güvende müşterinin de iyi niyeti önemlidir. Müşteriler markayı kişiselleşmiş bir varlık gibi düşünebilmekte ve her zaman bu markadan uzun vadeli ve güvenli reaksiyonlar göstermesini beklemektedirler. Beklenti karşılandığı sürece de markadan tatmin olma (Swaen ve Chumpitaz, 2008, s.13); (Eren ve Erge 2012, s. 4458) ve tatmin düzeyi arttıkça da markaya bağlılı̆̆ın oluşacağı 
beklenmektedir. Güven, bir işlemde tarafların beklenti ve riskleri karşılıklı olarak üstlenip, beklentilere göre hareket etmesi olarak tanımlanabilir. Kişi, beklediği bir olayın gerçekleşmesi durumunda güven duyar. Güven, risk karşısında diğer tarafa inanma isteğidir. $\mathrm{Bu}$ istek diğer tarafa ait geçmiş tecrübelerin anlaşılmasından kaynaklanır. Güven, diğer tarafın olumsuz sonuca neden olma ihtimali olmasına rağmen kişide sadece olumlu sonuç olacağı beklentisi oluşturur (Lau ve Lee, 1999, s.343). Kendilerine uygun tüketici grubunu belirledikten ve elde ettikten sonra işletmeler artık bu tüketicilerle sağlam ilişkiler geliştirmeye başlamış ve aralarında güven kavramı oluşturma adına çalışmalarda bulunmuşlardır (Bennet, 1996). Tüketici grubuyla aralarında güven duygusunu kazanan işletmeler bu sayede piyasadaki diğer rakip işletmelere karşı da bir üstünlük sağlamışlardır. Marka güveni ise, tüketicinin bir markanın iddia ettiği fonksiyonları gerçekleştirme yeteneğine olan inancıdır (Chaudhuri ve Holbrook, 2001, s. 82). Tüketicide marka sadakati oluşturmak için öncelikle tüketicinin güvenini kazanmak gereklidir. Çünkü söz verme ve sözün yerine getirilme sürecinde sağlam ilişkilerin kurulması için güven önemli bir faktördür (Selvi vd., 2007, s.109).

Amerika Pazarlama Derneği 2012 yılında marka tercihini, müşterilerin kalbinin ve aklının bir markasının gücü göstergelerinden biri olarak tanımlayarak, fiyat ve mevcudiyette eşitlik varsayımları altında hangi markaların tercih edildiğini temsil ettiğini ifade etmektedir. Müşteriler satın alma karar sürecinin karmaşıklığını azaltmak için marka tercihleri oluştururlar (Hwang ve Chihyung, 2013). Tüketici marka tercihi üç bileşeni temsil eder: bilişsel, duyuşsal ve davranışsal (Bartels ve Jhonson, 2015). Müşteriler satın alma karar sürecinin karmaşıklığını azaltmak için marka tercihleri oluştururlar (Gensch, 1987). Marka tercihi oluşturma süreci şunları içerir: birincisi, birçok markaya maruz kalmak, ardından karmaşık bir satın alma kararı sürecidir. Tüketici ihtiyacının niteliği, markaya ait özelliklerin tüketiciler tarafından algılanışı gibi pek çok faktörün belirlediği marka tercihi en genel ifade ile "Tüketici ihtiyaçları ile tüketicinin markaya ilişkin inanç ve tutumlarının etkisiyle markanın değerlendirilmesi sonucunda satın alma karar sürecinde belirli bir markanın tercih edilmesi" olarak ifade edilmektedir (Aktuğlu, 2004, s. 36). Müşteriler genellikle bazı markaları hafizalarından kaldırırlar; daha sonra, kalan ürün markaları arasında müşteriler, gelecekte satın almayı düşündükleri markaları ezberler (Hwang ve Chihyung, 2013). Keller'ın (1993, s.8) belirttiği gibi, tüketicilerin firmaların pazarlama faaliyetlerine verdiği tepki, alg1, tercih ve davranışları açısından ölçülebilir. Başka bir deyişle, güçlü markalar marka öz sermayesini o da marka tercihini artırmaktadır. Marka tercihi, tüketicilerin alışkanlıkları veya geçmişteki deneyimlerine bağlı olarak rakip markaların içinden bir markayı seçme davranışı sergilemesidir (Aktuğlu ve Temel, 2006). Özgünlük deneyimleri, özgün ürün ve bu ürünle bir deneyim yaşayan kişinin etkileşimi yoluyla, birlikte yaratılmaktadır (Chalmers, 2007). Özgün markaların tüketicilerine yaşattıkları deneyimler, kişilerin marka tercihleri üzerinde belirleyici etkiye sahiptir. 


\section{Tasarım ve Yöntem}

\subsection{Araştırmanın Modeli ve Hipotezler}

Araştırmanın modeli Şekil 1'de yer almaktadır.

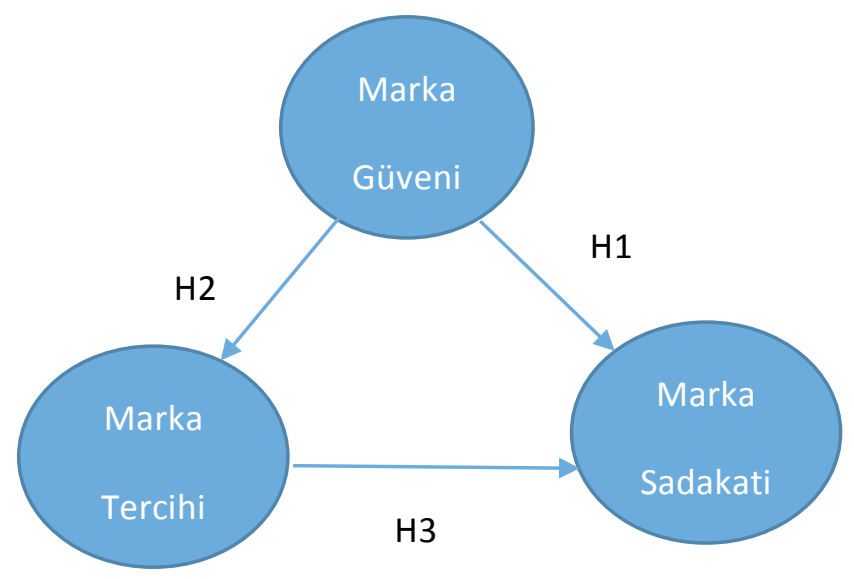

Şekil 1 Araştırmanın Modeli

Araştırma modeline dayalı olarak oluşturulan araştırma hipotezleri aşağıda verilmiştir:

a) $\mathbf{H}_{\mathbf{1}}=$ Marka Güveni Marka Sadakatini olumlu yönde etkilemektedir.

b) $\mathbf{H}_{2}=$ Marka Güveni Marka Tercihini olumlu yönde etkilemektedir.

c) $\mathbf{H}_{3}=$ Marka Tercihi Marka Sadakatini olumlu yönde etkilemektedir.

\subsection{Evren ve Örneklem}

Boya kalem sektörü satış personelleri ile yapılan ön görüşmelerde boya kalemi markasının seçimine yönelik en önemli ve etken karar verici kişilerin okul öğretmenlerinin olduğu belirtilerek, bu sektörde pazarlama satış çabalarının da bu nedenle öncelikle okul öğretmenlerine yönelik yapıldığ tüketicilerin kırtasiyelere gittiklerinde okul öğretmenlerinin öncelikle kendilerinden istedikleri marka boya kalemi satın aldıkları belirlenmiştir. Milli Eğitim Bakanlığı 2017 y1lı istatistiklerine göre (www.sgb.meb.gov.tr, 2017) Türkiye'de toplam 993.794 öğretmen mevcut olup, bunlardan 863.126's1 devlette, 130.868'i özel okullarda yer almaktadır. Araştırma verilerinin toplanması İstanbul'da, kırtasiye sektöründe yer alan ve pazarın büyük çoğunluğunu elinde tutan üç boya kalemi markasına yönelik (Faber Alman menşei, Bic - Fransa menşei, Fatih - Türk menşei) olarak kamu ya da özel okullarda kotalamaya dayalı rassal örnekleme yöntemine göre toplam 459 okul öğretmenleriyle yüz yüze anket yönetimine dayalı olarak gerçekleştirilmiştir. Söz konusu devlet okulunda görevli öğretmenlerin önemli bölümü ankete katılmaktan çekindikleri için anketlerin büyük çoğunluğu özel okul öğretmenleriyle gerçekleştirilmiştir. Görüşme yapılan kişiler İstanbul ilinde yer alan Milli Eğitim Bakanlığı'na bağlı okul listesinden rastgele seçilmesiyle ve bu seçilen okullarla yapılan telefon görüşmesi sonunda randevu alınmasıyla anket uygulması gerçekleştirilmiş, şayet ilgili okuldan randevu verilmediyse listeden tesadüfi seçilen diğer okuldan alınan 
randevuyla gerçekleştirilme yoluna gidilmiştir. Okul listesinden rastgele seçilerek randevu alınan toplam 51 okul ziyaret edilmiş ve her okuldan da Faber, Bic ve Fatih markasından birini seçen üçer öğretmle görüşelerek, toplamda her okulda dokuz öğretmenle anket uygulaması gerçekleştirilmiştir. Ankette okul öğretmenlerine üç marka bu üç markadan öğrencilere satın almaları için tavsiye ettiği hangi marka olduğu sorularak diğer soruları cevaplamaları istenmiş olup eğer bu üç markanın dışında başka

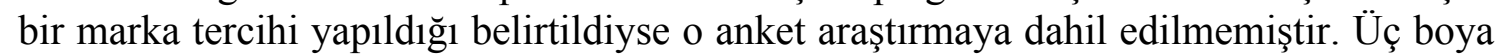
markası kaleminin pazar paylarının kesin bilinmemesi nedeniyle her üç marka için eşit sayıda kişiyle görüşülmüştür. Saha araştırma öncesi 10 kişiyle pilot uygulama gerçekleştirilerek soruların anlaşılıp anlaşılamadığı test edilmiş ve soru listesinde varsa eksiklikler giderildikten sonra saha da uygulamaya geçilmiştir. Söz konusu anketlerden 402 tanesi çalışma için uygun olarak değerlendirilerek \%95 güven aralığında örneklem sayısı yeterli kabul edilmiştir (Saunders, 2011).

\subsection{Veri Toplama Yöntemi ve Kullanılan Ölçme Aracı}

Marka Güveni ölçeği için Delgado-Ballester'ın (2004, s.579) çalışmasından alınmış dört ifade ile ölçülürken, marka sadakati ölçeği için, Özdemir ve Koçak (2012)'ın çalışmalarında yer alan tutumsal marka sadakati ve davranışsal marka sadakati ölçekleri birleştirilerek elde edilen 5 ifadeli ölçek, marka tercihi ölçeği için Chang ve Liu (2009)'nun geliştirdiği 4 ifadeli ölçek, kullanılmıştır. Toplanan veriler öncelikle ölçekler bazında SPSS paket programından faydalanılarak açıklayıcı faktör ve güvenirlik analizlerine tutularak istatiksel olarak anlamlılık göstermeyen sorular ölçeklerden çıkarılarak ölçekler çalışılabilir hazır hale getirilmişlerdir. Yapılan çalışmada 5'li Likert tipi iki ölçek kullanılmıştır. Ölçeklerde (1=kesinlikle katılmıyorum ve $5=$ kesinlikle katılıyorum) ifade eden yargılara yer verilmiştir.

\section{Bulgular ve Tartışma}

\subsection{Tanımlayıcı ve Açıklayıcı Bulgular}

Yapılan analizde, çalışmada kullanılan verilerin normal dağılım gösterdiği belirlenmiştir. Okul öğretmenlerinin çalıştığı kurum tipi, branşı, cinsiyet, yaşı ifade eden demografik değişkenlere yönelik tanımsal istatistikleri ve ilgili ölçek soruları aşağıda Tablo 1' ve 2 ve 3'de gösterilmiştir.

Tablo 1 Markaların Dağılımı

\begin{tabular}{|l|c|c|}
\hline \multicolumn{1}{|c|}{ MARKALAR } & Frekans & Yüzde \\
\hline FABER CASTELL & 134 & 33,3 \\
\hline BIC & 134 & 33,3 \\
\hline FATİH & 134 & 33,3 \\
\hline Toplam & 402 & 100 \\
\hline
\end{tabular}


V. Önen 10/2 (2018) 609-626

Tablo 2 Katılımcıların Demografik Özellikleri

\begin{tabular}{|c|c|c|c|c|c|}
\hline Demografik Özellikler & Frekans & Yüzde & Demografik Özellikler & Frekans & Yüzde \\
\hline Cinsiyet & & & Kurum Tipi & & \\
\hline Kadın & 252 & 62,7 & Devlet & 71 & 18 \\
\hline Erkek & 150 & 37,3 & Özel & 331 & 82 \\
\hline Toplam & 402 & 100 & Toplam & 402 & 100 \\
\hline Branşı & Frekans & Yüzde & Branşı & Frekans & Yüzde \\
\hline BEDEN & 10 & 2,5 & MATEMATİK & 39 & 9,7 \\
\hline EDEBIYYAT & 32 & 8,0 & MÜZİK & 2 &, 5 \\
\hline FELSEFE & 2 &, 5 & OKUL ÖNCESİ & 50 & 12,4 \\
\hline FEN & 16 & 4,0 & SINIF & 66 & 16,4 \\
\hline FİİK & 18 & 4,5 & TARİH & 34 & 8,5 \\
\hline İNGİLIZCE & 58 & 14,4 & TÜRKÇE & 57 & 14,2 \\
\hline KİMYA & 18 & 4,5 & Toplam & 402 & 100 \\
\hline Yaş & Frekans & Yüzde & & & \\
\hline $25-29$ & 46 & 9,6 & & & \\
\hline $30-36$ & 364 & 76,2 & & & \\
\hline $37-42$ & 50 & 10,5 & & & \\
\hline $43-49$ & 17 & 3,6 & & & \\
\hline $50-56$ & 1 & ,2 & & & \\
\hline Total & 402 & 100 & & & \\
\hline
\end{tabular}

Tablo 3 Ölçeklere Ait Sorular

\begin{tabular}{|c|c|c|c|}
\hline Soru & Marka Sadakati & Marka Güveni & Marka Tercihi \\
\hline 1 & $\begin{array}{l}\text { Bu markayı satın almaya } \\
\text { devam edeceğim . }\end{array}$ & Bu markaya güvenirim & $\begin{array}{l}\text { Diğer markalardan önce bu } \\
\text { markayı satın almayı düşünürüm }\end{array}$ \\
\hline 2 & $\begin{array}{l}\text { Bu markaya bağımlılığım söz } \\
\text { konusudur }\end{array}$ & $\begin{array}{l}\text { Bu marka beklentilerimi } \\
\text { karşılar. }\end{array}$ & $\begin{array}{l}\text { Diğer markaların özellikleri bu } \\
\text { marka kadar iyi olsa bile yine bu } \\
\text { markayı tercih ederim }\end{array}$ \\
\hline 3 & $\begin{array}{l}\text { Bu ürünü tekrar satın almam } \\
\text { gerektiğinde yine bu markayı } \\
\text { tercih ederim }\end{array}$ & $\begin{array}{l}\text { Bu marka ürünler ile ilgili bir } \\
\text { problemim olduğunda, } \\
\text { firmanın bu problem } \\
\text { çözeceğine güvenirim. }\end{array}$ & $\begin{array}{l}\text { Diğer markalar daha iyi teklifler } \\
\text { önerse de yine bu markayı tercih } \\
\text { ederim }\end{array}$ \\
\hline 4 & $\begin{array}{l}\text { Bu markaya, diğer } \\
\text { markalardan daha fazla ödeme } \\
\text { yapabilirim }\end{array}$ & $\begin{array}{l}\text { Bu marka beni asla hayal } \\
\text { kırıklığına uğratmaz. }\end{array}$ & $\begin{array}{l}\text { Daha sonraki satın alımlarda yine } \\
\text { bu markayı tercih ederim }\end{array}$ \\
\hline 5 & $\begin{array}{l}\text { Bu markaya tutku ile } \\
\text { bağliyım. }\end{array}$ & & \\
\hline
\end{tabular}

\subsection{Hipotezlere İlişkin Bulgular}

Ölçeklere ait yapılan açıklayıcı faktör ve güvenirlik analizi sonuçları Tablo 4'de gösterilmektedir.

Tablo 4 Güvenirlik ve Faktör Analizi Sonuçları

\begin{tabular}{|l|c|c|c|c|c|}
\hline Ölçekler & $\begin{array}{c}\text { Cronbach } \\
\text { alpha }\end{array}$ & KMO & $\begin{array}{c}\text { Barlett } \\
\text { Sigma }\end{array}$ & $\begin{array}{c}\text { Toplam Varyansın } \\
\text { Açıklama Oranı \% }\end{array}$ & Soru Sayıs1 \\
\hline Marka Güveni & 89,7 & 0,81 & 0,00 & 76,34 & 4 \\
\hline Marka Sadakati & 92,1 & 0,88 & 0,00 & 76,2 & 5 \\
\hline Marka Tercihi & 91,2 & 0,84 & 0,00 & 79,1 & 4 \\
\hline
\end{tabular}

Analiz sonrasında, marka değeri ve marka aşkı ölçeklerine ait elde edilen değerleri Tablo 5'de gösterilmektedir. 
Tablo 5 Ölçeklerin Ortalama Değerleri

\begin{tabular}{|l|c|c|c|c|c|c|}
\hline Ölçekler & $\begin{array}{c}\text { Örneklem } \\
\text { Sayısı }\end{array}$ & En Düşük & En Yüksek & Ortalama & $\begin{array}{c}\text { Standart } \\
\text { Sapma }\end{array}$ & Varyans \\
\hline Marka Güveni & 402 & 1,00 & 5,00 & 3,07 & 1,12 & 1,25 \\
\hline Marka Sadakati & 402 & 1,00 & 5,00 & 3,11 & 1,07 & 1,16 \\
\hline Marka Tercihi & 402 & 1,00 & 5,00 & 3,07 & 1,11 & 1,24 \\
\hline Geçerli Örnek Sayısı & 402 & & & & & \\
\hline
\end{tabular}

Tablo 5' te görüleceği üzere, 5'li ölçek üzerinden Marka Güveni yüzlük değer üzerinde (\%61), Marka Sadakati (\%62), Marka Tercihi (\%61)olarak gerçekleşmiştir. Elde edilen değerler her üç ölçek açısından bakıldığında ortalamanın biraz üzerinde olduğu gözükmektedir.

Tablo 6 Ölçeklerin Markalara Göre Tanımsal İstatistikleri

\begin{tabular}{|c|c|c|c|c|c|c|}
\hline $\begin{array}{l}\text { Marka } \\
\text { Bileşenleri }\end{array}$ & Markalar & Örneklem & En Düşük & En Büyük & Ortalama & Std. Sapma \\
\hline \multirow{3}{*}{ 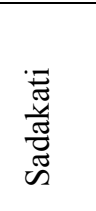 } & Faber Castell & 134 & 2,40 & 5,0 & 3,93 & 0,49 \\
\hline & Bic & 134 & 1,0 & 5,0 & 2.91 & 1.07 \\
\hline & Fatih & 134 & 1,0 & 5,0 & 2,37 & 1,06 \\
\hline \multirow{3}{*}{$\frac{\tilde{g}}{\bar{\pi}}$} & Faber Casteel & 134 & 1,0 & 5,0 & 2,46 & 1,00 \\
\hline & Bic & 134 & 1,0 & 5,0 & 3,02 & 1,12 \\
\hline & Fatih & 134 & 1,0 & 5,0 & 3,99 & 0,54 \\
\hline \multirow{3}{*}{ 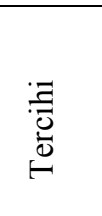 } & Faber Castell & 134 & 1,0 & 5,0 & 3,99 & 0,54 \\
\hline & Bic & 134 & 1,0 & 5,0 & 3,02 & 1,12 \\
\hline & Fatih & 134 & 1,0 & 5,0 & 2,46 & 1,00 \\
\hline
\end{tabular}

Her üç marka özelliği yönünden Tablo 6'ya bakıldığında bakıldığında marka güveni yönünden birinci Faber Castell, ikinci Bic, üçüncü de Fatih markası, marka tercihi yönünden birinci Faber Castell, ikinci Bic ve üçüncü Fatih markası, marka sadakati yönünden birinci Faber Castell, ikinci Bic, üçüncü Fatih markası çıkmış olup, tüm ölçeklerde Faber Castell birinci, Bic ikinci ve Fatih markası üçüncü olarak ortaya çıkmıştır.

Bunlara ilave olarak piyasada 1 kutu boya kalemi fiyatı Faber için 10 tl, Bic için 17 tl ve Fatih markası için 9,5 tl olduğu belirlenmiştir.

Tanımsal özellikleri Tablo 5'te yer alan marka sadakati ile marka güveninin marka sadakati üzerindeki etkisinin belirlenmesine yönelik yapılan regresyon analizine ilişkin model özeti ve etkileşim katsayıları sonuçları Tablo 7'de gösterilmektedir. 
Tablo 7 Model Özeti ve Etkileşim Katsayıları

\begin{tabular}{|c|c|c|c|c|c|c|}
\hline \multicolumn{7}{|c|}{ Bağımlı Değişken: Marka Sadakati } \\
\hline $\begin{array}{l}\text { Bağımsız } \\
\text { Değişken }\end{array}$ & $\mathrm{F}$ & $\mathrm{P}$ & $\begin{array}{c}\text { B } \\
\text { katsayıs1 }\end{array}$ & S.H. & $\mathrm{T}$ & VIF \\
\hline (Sabit) & \multirow[b]{2}{*}{1567,81} & \multirow[b]{2}{*}{0,00} & 0,18 & 0,07 & 2,39 & \multirow[b]{2}{*}{1,0} \\
\hline Marka Güveni & & & 92 & 0,2 & 35,59 & \\
\hline $\mathbf{R}^{2}=, 89$ & Düzeltiln & $\mathbf{R}^{2}=, 79$ & & Durbin & on kat & 1,64 \\
\hline
\end{tabular}

Yapılan analizde $F$ istatistiğinin, $F=1567,8$ olup ve anlamlı görülldüğ̈̈ $(p=0,00)$, düzeltilmiş $\mathrm{R}$ kare değerinin 0,80 olduğu görülmüş olup, marka güveninin marka sadakatini 0,80 oranda izah ettiğini söylenebilir. Durbin-Watsson test tedeğeri 1,5-2,3 arasında olup otokorelasyon bulunmamaktadır. Tablo 7'de ilgili regresyon denkleminin etkileşim katsayılarına bakıldığında sabit katsayı 0,185 olarak \%95 güven aralağında anlamlı $(\mathrm{p}=0,017)$ tespit edilmiş olup, Marka Güveni bağımsız değişkeni de 0,93 değerinde $\% 95$ güven aralağında anlamlı $(\mathrm{p}=0,00)$ oarak belirlenmiştir. VIF değeri 10'dan küçük olup (Gürbüz ve Şahin, 2016, s. 273) çoklu bağlantı problemi bulunmamaktadır. Buna göre, Marka Sadakati ile Marka Güveni arasındaki ilişkiyi ifade eden regresyon denklemi aşağıdaki, biçimde gösterebilir.

Marka Sadakati $=0,18+0,93 *$ Marka Güveni

Böylelikle, marka sadakati ile marka güveni arasında pozitif yönlü bir ilişki olup, beher bir marka güvenindeki artış, marka sadakatini 0,93 birim pozitif olarak 0,18 lik sabit etkiye ilave olarak artırmaktadır.

Tanımsal özellikleri Tablo 5'te yer alan marka güveninin marka tercihi üzerindeki etkisinin belirlenmesine yönelik yapılan regresyon analizine ilişkin model özeti ve etkileşim katsayıları sonuçları Tablo 8'de gösterilmektedir.

Tablo 8 Model Özeti ve Etkileşim Katsayıları

\begin{tabular}{|c|c|c|c|c|c|c|}
\hline \multicolumn{7}{|c|}{ Bağımlı Değişken: Marka Tercihi } \\
\hline $\begin{array}{l}\text { Bağımsız } \\
\text { Değişken }\end{array}$ & $\mathrm{F}$ & $\mathrm{P}$ & B katsayısı & S.H. & $\mathrm{T}$ & VIF \\
\hline Mark Güveni & 5328,70 & 0,00 & 99 & 0,2 & 35,59 & 1,0 \\
\hline $\mathbf{R}^{2}=, 93$ & \multicolumn{3}{|c|}{ Düzeltilmiş $\mathbf{R}^{2}=, 93$} & \multicolumn{3}{|c|}{$\begin{array}{l}\text { Durbin-Watson katsayısı= } \\
1,92\end{array}$} \\
\hline
\end{tabular}

Yapılan analizde $F$ istatistiğinin, $F=5328,7$ olup ve anlamlı görüldüğü $(p=0,00)$, düzeltilmiş $\mathrm{R}$ kare değerinin 0,93 olduğu görülmüş olup, marka güveninin marka sadakatini 0,93 oranda izah ettiğini söyleyebiliriz. Durbin-Watsson test tedeğeri 1,5-2,3 arasında olup otokorelasyon bulunmamaktadır. Tablo 8'de ilgili regresyon denkleminin etkileşim katsayılarına baktığımızda sabit katsayı -0,40 olarak \%95 güven aralağında anlamlı olmadığı ( $\mathrm{p}=0,38>0,05$ olup) tespit edilmiş olup, Marka Güveni bağımsız değişkeni de 0,99 değerinde $\% 95$ güven aralığında anlamlı $(\mathrm{p}=0,00)$ oarak belirlenmiştir. VIF değeri 10'dan küçük olup çoklu olup (Gürbüz ve Şahin, 2016, s. 273) bağlantı problemi yoktur. Buna göre, Marka Tercihi ile Marka Güveni arasındaki ilişkiyi gösteren regresyon denklemi aşağıdaki şekilde gösterilmektedir.

Marka Tercihi $=0,99 *$ Marka Güveni

Marka tercihi ile marka güveni arasında pozitif yönde bir ilişki olup beher bir marka güvenindeki bir birim artış marka tercihini 0,99 birim artıtmaktadır. 
Tanımsal özellikleri Tablo 5'te yer alan marka sadakati ile marka tercihinin marka sadakati üzerindeki etkisinin belirlenmesine yönelik yapılan regresyon analizine ilişkin model özeti ve sonuçları Tablo 9'da gösterilmektedir.

Tablo 9 Model Özeti ve Etkileşim Katsayıları

\begin{tabular}{|c|c|c|c|c|c|c|}
\hline \multicolumn{7}{|c|}{ Bağımlı Değişken: Marka Sadakati } \\
\hline $\begin{array}{l}\text { Bağımsız } \\
\text { Değișken }\end{array}$ & $\mathrm{F}$ & $\mathrm{P}$ & $\begin{array}{c}\text { B } \\
\text { katsay1s1 }\end{array}$ & S.H. & $\mathrm{T}$ & VIF \\
\hline (Sabit) & \multirow[b]{2}{*}{1101,14} & \multirow[b]{2}{*}{0,00} & 0,43 & 0,095 & 5,13 & \multirow[b]{2}{*}{1,0} \\
\hline Marka Tercihi & & & ,86 & 0,026 & 33,18 & \\
\hline $\mathbf{R}^{2}=, 73$ & \multicolumn{3}{|c|}{ Düzeltilmiș $\mathbf{R}^{2}=, 73$} & \multicolumn{3}{|c|}{ Durbin-Watson katsayısı $=1,89$} \\
\hline
\end{tabular}

Yapılan analizde $F$ istatistiğinin, $F=57983$ olup ve anlamlı görüldüğü $(p=0,00)$, düzeltilmiş $\mathrm{R}$ kare değerinin 0,73 olduğu görülmüş olup, marka güveninin marka sadakatini 0,73 oranda izah ettiğini söyleyebiliriz. Durbin-Watsson test tedeğeri 1,5-2,3 arasında olup otokorelasyon bulunmamaktadır. Tablo 9' da ilgili regresyon denkleminin etkileşim katsayılarına baktığımızda sabit katsayı 0,43 olarak \%95 güven aralağında anlamlı olduğu $(\mathrm{p}=0,00)$ tespit edilmiş olup, Marka Tercihi bağımsız değişkeni de 0,86 değerinde \%95 güven aralığında anlamlı $(\mathrm{p}=0,00)$ olarak belirlenmiştir. VIF değeri 10'dan küçük olup olup (Gürbüz ve Şahin, 2016, s. 273) çoklu bağlantı problemi bulunmamaktadir.

Buna göre, Marka Sadakati ile Marka Tercihi arasındaki ilişkiyi gösteren regresyon denklemi aşağıdaki şekilde gösterilmektedir.

\section{Marka Sadakati $=0,43+0,86 *$ Marka Tercihi}

Böylelikle, marka sadakati ile marka tercihi arasında pozitif yönlü bir ilişki olup, beher bir marka tercihindeki artış, marka sadakatini 0,86 birim pozitif olarak 0,43 lük sabit etkiye ilave olarak artırmaktadır.

Bu bulguların 1şığında marka güveni ile marka sadakati arasında literatürde tespit edilen benzer sonuçlara ulaşılmıştır. Bunlara ilave olarak marka güveni ile marka tercihinin yüksek seviyede ilişkili olması Chaudhuri ve Holbrook (2001)'ın yaptıkları çalışmada olduğu gibi güvenin tutumsal sadakat yarattığı ve markaya oluşan bu inançın etkisiyle markanın değerlendirilmesi sonucunda ilgili ürünlerin tercih edildiğini söyleyebiliriz. Marka tercihinin marka sadakatine etkisi bize müşterilerin olumlu bilşsel ve duyuşsal deneyimleri sonucunda yapılan marka tecihlerinin bir sonraki satın alma niyetlerinde ve tekrarlı almalarda aynı markaya yönlendirmesine sevk ederek bağlılığın oluşmasına ve dolayısıyla marka sadakatinin artmasına yol açması olarak izah edilebilir.

\section{Sonuç ve Tartışma}

Ölçeklerin, tüketiciler açısından yüzlük puanlama üzerinden değerlendirmelerine bakıldığında marka güveni (\%61), marka sadakati (\%62), marka tercihi (\%61) olarak gerçekleşmiş olup bu değerler ortalamanın çok az üzerinde olduğu değerlendirilerek her üç marka bileşeni açısından firmaların bu bileşenlerini iyileştirmesi gerekmektedir. Her üç marka ölçeğinin tamamında mevcut markaların başarı sıralaması Fabel Castell birinci, Bic markası ikinci ve Fatih markası üçüncü olarak ortaya çıkmıştır.Yapılan regresyon analizlerinde marka güveninin marka sadakati ile anlamlı ve pozitif yönde etkilediği tespit edilerek ilgili $\mathrm{H}_{1}$ hipotezi kabul edilmiştir. Buna göre marka güvenindeki artış marka sadakatini olumlu olarak artırmaktadır. Benzer şekilde marka güveni ve marka tercihi arasındaki ilişki de anlamlı ve pozitif yönde belirlenmiş olup 
ilgili $\mathrm{H}_{2}$ hipotezi kabul edilmiştir. Buna göre beher birim marka güvenindeki artış marka tercihini olumlu olarak artırmaktadır. Aynı şekilde marka tercihi ve marka sadakati arasındaki ilişki de anlamlı ve pozitif yönde belirlenmiş olup ilgili $\mathrm{H}_{3}$ hipotezi kabul edilmiştir. Buna göre marka tercihindeki artış marka sadakatini olumlu olarak artırmaktadır. Literatürde, marka sadakatine etki eden faktörlere bakıldığında genelde güven, memnuniyet, tutundurma, fiyat, algılanan değer, imaj, algılanan risk, tutundurma, algılanan kalite olarak yer almaktadır. Marka güveninin marka sadakati üzerinde güçlü ve olumlu etkisinin olduğu sonucuna yönelik çalışmalar da mevcuttur (Morgan ve Hunt, 1994; Lau ve Lee, 1999; Chaudhuri ve Holbrook, 2001; DelgadoBallester ve Alemán, 2001; Tsiotsou, 2010; Chiu vd., 2010). Daha önceki çalışmalarda olduğu gibi bu çalışmada da markaya olan güveninin marka sadakatini yüksek seviyede olumlu yönde desteklediği ortaya çıkmıştır. Dolayısıyla marka sadakatine giden yolda tüketicilerin markaya olan güven duygusuna yönelik ihtiyaç ve beklentilerin karşılanması gerekmektedir. Çalışmada marka güveninin aynı zamanda marka tercihini de olumlu yönde etkilediği belirlenmiştir. $\mathrm{Bu}$ nedenle tüketicilerin sunulan markayı tercih etmeleri için markaya olan güvenin önemli bir faktör olduğu düşünülmeli ve buna yönelik çalışmaların yapılması gerekmektedir. Marka sadakatinin satın alma istekliliğini olumlu yönde etkilediğine yönelik makalelerde bulunmakta ve bunu aslında beklenen bir sonuç olarak görülmeli. (Kim vd., 2007) sadakat tanımı çerçevesinde konuyu ele alındığında, çalışmada yer alan marka tercihi ölçümü, davranışsal sadakat yönünden müşterinin bir marka ya da hizmet için tercihini gösteren tekrar satın alma davranışını ifade ettiğini söylenebilir. Böylelikle araştırmada elde edilen marka tercihinin marka sadakatini olumlu ve yüksek seviyede etkilemsi bu açıdan açıklanabilinir. Özetle; markaya olan güven sadakati etkilemekte, tüketici sadık kaldığı markadan davranışşsal yönden tatmin kaldığı için ve memnun olduğu için aynı markayı tekrar satın almakta ya da tüketici güvendiği duyduğu markayı tercih etmekte ve aynı markayı satın alarak ona sadık kalarak kullanmaya devam etmektedir. Marka tercihinin marka güveni ile marka sadakati arasında aracılık rolü çalışmada test edilmemiştir ancak elde edilen sonuçlardan bunun neticesi öngörülmektedir. Zira marka güveni ile marka sadakati, marka güveni ile marka güveni ve marka tercihi ile marka sadakati aralarındaki tek başlarına etkileme katsayıları sırasıyla 0,$93 ; 0,99$ ve 0,86 olup oldukça yüksek değerler belirlendiği için marka tercihinin bu etkileme seviyesini daha da artıracak bir aracılık rolü bulunmadığı ifade edilebilir. Çalışma literatürde yer alan pek çok marka güveni ve marka sadakati arasındaki ilişkiyi ortaya koyan çalışmalardaki benzer sonucu kırtasiye boya kalemi sektöründe de teyit ettirmiştir. Ayrıca, marka güveni bileşeninin gerek marka sadakatini gerekse de marka tercihini etkilemekte olduğu belirlendiğinden dolayı marka güveninin diğer iki marka bileşenin gelişmesine yönelik ortak bir bileşen olduğu söylenebilir. Özellikle marka güveni ile marka sadakati ve tercihi arasında yüksek seviyede anlamlı bir etkilemenin ortaya çıkması bunun önemini daha da vurgulamaktadır. Bu nedenle önce müşterilerin markaya olan güven inancı oluşturulması buna yönelik müşterilerin ihtiyaç ve beklentileri karşılanması, müştrilerin sorunlar yaşandığında markanın bu sorunları çözebileceğine güven duyması ve müşterileri asla hayal kırıklığına uğratmaması gerekmketedir. İşletmenin müşterilerine bir vaadi olarak sunulan marka, ürüne yönelik belirli bir talep ve bağlılık oluşturarak satışların devamını sağlamakta ve pazardaki pozisyonunu güçlendirmektedir. Böylelikle müşterilerin markaya olan güvenin markaya olan bağlılığını ve akabinde de marka sadakatini oluşturmaktadır. Boya kalemi firmaları tüketcilerin zihninde oluşturulacağı iyi bir güven duygusuyla tüketiclerin diğer markaları düşünmemesini, kullandığı ürünü değiştirmemesini aynı 
ürünü kullanmayı tercih etmesini ve böylelikle tekrarlı satın almasını sağlayacaktır. Dolayısı ile bilişsel, duyuşsal ve davranışsal yönden sağlanan tatmin daha fazla bağlılığa ve karlılığa dönüşecektir. Ele alınan boya kalemi sektöründe; marka güveni, marka bağlılı̆̆ı ve marka tercihleri arasındaki etkileme seviyeleri yüksek çıkmakla beraber, ilgili sektör firmalarının bu konudaki ölçülen performans değerleri ortalama seviyenin biraz üzerinde çıktığı görülmüştür. Bu nedenle söz konusu sektör firmalarının her üç marka bileşeni seviyelerini iyileştirmesi ve arttırması gerekmektedir. Bic markasının rakip markalardan fiyatı yaklaşık \%70 daha pahalı olmasına rağmen her üç marka bileşeni yönünden ikinci sırada yer aldığıdan olup teklif edilen fiyat - üç bileşen açsından marka performansına bakıldığında en düşük seviyedeki firma görünümündedir. Bic markasının pazara 1990 yılından sonra girdiği, Faber markasının ise bundan çok daha önce piyasada yer aldığı öğrenildiğinden dolayı, Bic markasının pazarda marka bilinirliğinin daha düşük olabileceği nedeniyle böyle bir sıralamanın oluştuğu söylenebilir. Fatih markasının ise piyasada en eski marka olmasına (1960) ve en düşük fiyatlı marka olmasına rağmen her üç marka bileşeni açısından sıralamada son sırada yer almış olması bu markanın kalite algısının müşteriler açısından düşük seviyede algılandığını düşündürmektedir. Faber markası sıralamada fiyat ve üç marka bileşeni yönünden performans sıralamasında birinci sırada yer almasına rağmen, öğretmenler tarafindan niçin marka güveni, marka sadakati ve marka tercihi yönünden yeterince iyi seviyede görülmediğinin bilinmesi gerekmektedir. $\mathrm{Bu}$ sebeplerle tüm bu soruların cevaplanmasına yönelik olarak ileriye dönük sektör firmaların bu konularda nitel araştırma yaptırmaları tavsiye edilmektedir. Her üç markanın da üç marka bileşeni yönünden seviyesinin yeteri kadar iyi olmaması olası bir şekilde piyasaya yeni bir markanın girmesine yol açarak pazar ve müşteri kaybına neden olması söz konusu olabilir.

Sonuç olarak bu çalışmada markaya duyulan güvenin marka tercihini ve marka sadakatini anlamlı ve pozitif yönde yüksek seviyede etkilemekte olduğu, marka tercihinin de marka sadakatini anlamlı ve pozitif yönde yüksek seviyede etkiledeği tespit edilmiştir. $\mathrm{Bu}$ çalışma neticesinde marka güveni, marka sadakati ve marka tercihinin birbirlerine etkilerinin ortaya konulması marka yönetimi açısından çalışanlara ve literature destek sağlayacaktır. Ancak, marka güveni, marka sadakati ve marka tercihini etkileyen bir çok başka faktörler de; örneğin marka farkındalığı, marka özgünlüğü, marka kimliği, marka deneyimi, tüketici sosyolojik, psikolojik faktörleri gibi bileşenler de söz konusudur. Bu nedenle marka yönetimi açısından bu üç marka bileşenine etki edebilecek diğer faktörler yönünden de çalışmaların yapılarak bu çalışmadaki bulguların karşılaştırılması tavsiye edilir. Çalışma kırtasiye boya kalem sektöründe yapılmış olup başka sektörlerde de marka güveni, marka sadakati ve marka tercihi arasındaki ilişkilere yönelik çalışmaların yapılarak sonuçların kıyaslanmasında fayda görülmektedir. Ayrıca, araştırmanın İstanbul dışındaki diğer büyük illerde ve çoğunluğu devlet okullarında yeralan öğretemenlerle yapılarak sonuçlarının karşılaştırılmasında fayda görülmektedir. 


\section{KAYNAKÇA}

Aktuğlu, I.K.. (2004). Marka Yönetimi, Birinci Baskı, İletişim Yayınları, İstanbul, 231s.

Aktuğlu, I.K ve Temel, A. (2006). Tüketiciler Markalarını Nasıl Tercih Ediyor?,(Kamu Sektörü Çalışanlarının Giysi Markalarını Tercihini Etkileyen Faktörlere Yönelik Bir Araştırma). Selçuk Üniversitesi Sosyal Bilimler Enstitüsü Dergisi, 2006, 15: 43-59. Selçuk Üniversitesi Sosyal Bilimler Enstitüsü Dergisi, 15, 43-59.

Bartels, D. M., and Johnson, E. J. (2015). Connecting cognition and consumer choice. Cognition, 135, 47-51.

Benett R. (1996). "Relationship Formation and Governance in Consumer Markets: Transactual Analysis versus The Behaviorist Aproach", Journal of Marketing Research, 12, 417436i.doi:10.1080/0267257X.1996.9964425.

Chalmers, T.D. (2007). “Advertising Authenticity: Resonating Replications of Real Life”, European Advences in Consumer Research, 8, 442-443.

Chaudhuri, A., and Holbrook, M. B. (2004). "The Chain of Effects from Brand Trust and Brand Affect to Brand Performance: The Role of brand Loyalty", Journal of Marketing, 65(2), 81-93.

Chang, H.H and Liu, Y.M. (2009). "The Impact of Brand Equity on Brand Preference And Purchase Intention in the Services Industries", The Service Industries Journal. 29 (12), 1687-1706.

Chiu, C.M., Huang, HY. and Yen, CH. (2010). "Antecedents of trust in online auctions, Electronic Commerce Research and Applications”, 9(2), 148-159.

Cyr, D., Hassanein, K., Head, M., and Ivanov, A. (2007). The role of social presence in establishing loyalty in e-service environments. Interacting with computers, 19(1), 43-56.

Dick, A.S., ve Basu, K. (1994). "Customer loyalty: toward an integrated conceptual framework. Journal of the academy of marketing science”, 22(2), 99-113.

Delgado-Ballester, E. (2004). Applicability of a brand trust scale across product categories: A multigroup invariance analysis. European Journal of Marketing, 38(5/6), 573-592.

Devrani, Ö. G. D. T. K. (2009). Marka Sadakati Öncülleri: Çalışan Kadınların Kozmetik Ürün Tüketimi Üzerine Bir Çalışma. Süleyman Demirel Üniversitesi İktisadi ve İdari Bilimler Fakültesi Dergisi, 14(3).

Eller, K.L. (1993). "Conceptualizing, measuring, and managing customer-based brand Equity”, The Journal of Marketing 57(1): 1-22.

Eren, S., ve Erge, S.A. (2012). Marka Güveni, Marka Memnuniyeti ve Müşteri Değerinin Tüketicilerin Marka Sadakati Üzerine Etkisi, Journal of Yasar University, 26 (7), 44554482. doi:10.19168/jyu.39018.

Evanschitzky, H., Iyer, G. R., Plassmann, H., Niessing, J., and Meffert, H. (2006). The relative strength of affective commitment in securing loyalty in service relationships. Journal of Business Research, 59(12), 1207-1213.

Gensch,D. (1987). "A two-stage disaggregate attribute choice model”, Marketing Science, 6(3), pp.223-231.

Grimm, P. (2005). "Ab components' impact on brand preference", Journal of Business Research, 58, pp.508-517.

Gürbüz, S., ve Şahin, F. (2016). Sosyal bilimlerde araştırma yöntemleri: Felsefe-yöntem-analiz, 3. Baskı, Ankara: Seçkin Yayıncılık. 
Harris, L., and Goode, C. (2004). "The Four Levels of Loyalty and Pivotal Role of Trust:A Study of Online Service Dynamics", Journal of Retailing, 80, 139-158. doi: 10.1016/j.jretai.2004.04.002.

Hwang, J., and Chihyug, O. (2013), "The antecedents and consequence of consumer attitudes toward restaurant brands: A comparative study between casual and fine dining restaurants", International Journal of Hospitality Management, pp121 -131.

Kara, Z .(2009). Yatırımcı İlişkileri Yönetiminde Güven ve Ekonomiye Etkisi' Afyon Kocatepe Ünv, İ.̇.B.F. Dergisi (C.X I,S I, 2009),s.281.

Kim, K. J., Jeong, I. J., Park, J. C., Park, Y. J., Kim, C. G., and Kim, T. H. (2007). The impact of network service performance on customer satisfaction and loyalty: High-speed internet service case in Korea. Expert Systems with Applications, 32(3), 822-831.

Lau, G., and Lee, S.H. (1999). "Consumers' Trust in a Brand and the Link to Brand Loyalty", Journal of Market Focused Management, 4, 341-370.

Miller, A., and William, G. A. (2003). "Complaint behavior as a factor in cruise line losses: An analysis of brand loyalty". Journal of Travel \& Tourism Marketing, 15(1), 77-91.

Morgan, R. and Hunt, M. (1994). "The Commitment Trust Theory of Relatiosnhip Marketing”, Journal of Marketing, 58, 20-38.

Oliver, R. L. (1999). Whence consumer loyalty?. the Journal of Marketing, 33-44.

Özdemir, M., Koçak, A. (2012). “İlişkisel Pazarlama Çerçevesinde Marka Sadakatinin Oluşumu ve Bir Model Önerisi”, Ankara Üniversitesi Siyasal Bilgiler Fakültesi Dergisi, 67(2), 127-156.

Saunders, M.NK. (2011). "Research Methods for Business Students", Second Edition, Prentice Hall Inc. New York

Selvi, S.T., Balakrishnan, P., Kumar, R., and Rajendar, K. (2007, December). Trust based grid scheduling algorithm for commercial grids. In Conference on Computational Intelligence and Multimedia Applications, 2007. International Conference on (Vol. 1, pp. 545-551). IEEE.

Swaen, V., and Chumpitaz, R.C. (2008). "Impact of Corporate Social Resposibility on Consumer Trust", Recherce At Applications on Marketing, 23(4), pp.7-33. doi:10.1177/205157070802300402.

Tsiotsous, R. (2010). "Brand loyalty through brand attachment and brand trust: A relationalperspective", In Proceedings of 6th Thought Leaders International Conference in Brand Management, 18-20.

Yoon, S.J., and Kim, J.H. (2000). "An Empirical Validation of a Loyal Model Based on Expectation Disconfirmation", Journal of Consumer Marketing, 17, 120-136.

Zeithaml, V.A., and Leonard L., Parasraman, A.(1996). "The behavioral consequences of service quality". Journal of Marketing, 60 (2), 31-46. http://sgb.meb.gov.tr/www/resmiistatistikler/icerik/64 


\title{
Analysis of Associaitions Between Brand Trust Brand Loyalty and Brand Preference: Stationery Industry Application
}

\author{
Vahap ÖNEN \\ İstanbul Okan University \\ Faculty of Applied Sciences \\ İstanbul, Turkey \\ orcid.org/0000-0001-8592-9430 \\ vahap.onen@okan.edu.tr
}

\section{Extensive Summary}

\section{Introduction}

An important way to avoid today's intense competition is to brand products and services. When we examine the properties of successful brands, it can be said that the brand trust has a great affect. If consumers have strong confidence in a brand, then it is possible to re-sellin of goods and services, prevent the switching of the customers, and ignore the negative effects on the brand. However, we believe that brand trust must be ensured in order for the brand preference to be achieved. In this respect, it si thought that brand trust is a important component that affect the formation of the brand preference and brand loyalty. There are not many studies in the literature evaluating the relationship between brand trust, brand loyalty and brand preference. It is thought that thhis study for

this reason will contribute to this issue. Loyalty is meaning that the customer wants to maintain a relationship with a firm or brand (Cyr et al., 2006). Customers with high brand loyalty are constantly buying brands and their brand loyalty is very high. Loyalty, the frequency of being a customer for a product or service, has always been defined as the preference for the same goods and services or firm (Zeithaml et al., 1996). Trust is belief

in the brand before it intends to buy it. Customers can think of the brand as a personalized entity and always expect long-term and trusted reactions from this brand. Satisfaction from the brand as long as it is expected (Swaen and Chumpitaz 2008, p.13); (Eren and Erge 2012, p.4458), and as the level of satisfaction increases, it is expected that the brand loyalty will become realized. Businesses that have gained a sense of trust among the consumer group have also gained an edge over other competing businesses on the market. It is necessary to gain the trust of the consumer firstly in order to create brand loyalty in the consumer. Trust is an important factor in establishing sound relationships in the process of promises and fulfillment (Selvi, 2007, p.109). 


\section{Model and Method}

The research model has been shown in Figure 1.

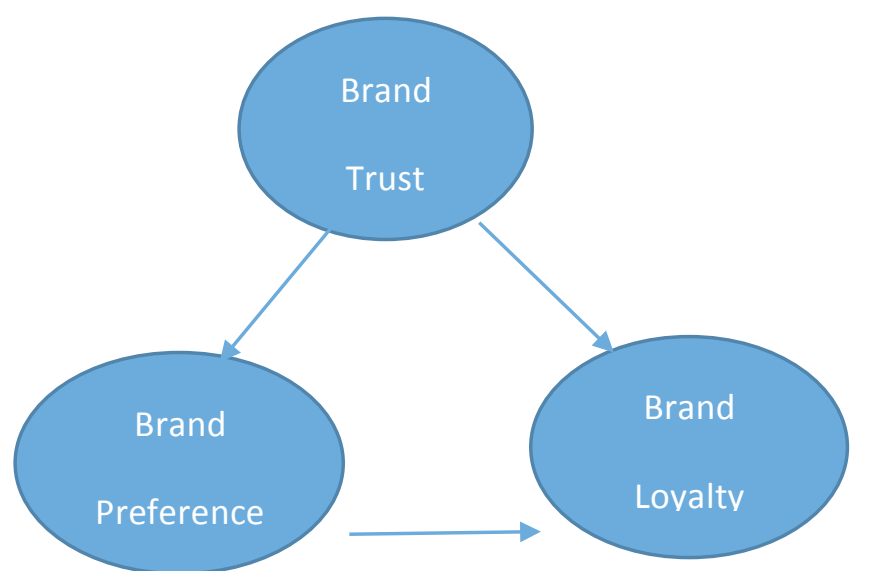

Figure 1 Research Model

a) $\mathbf{H}_{1}=$ There is a positive association between Brand Trust and Brand Preference

b) $\mathbf{H}_{2}=$ There is a positive association between Brand Trust and Brand Loyalty

c) $\mathbf{H}_{3}=$ There is a positive association between Brand Preference and Brand Loyalty

The survey conducted with 450 consumers in İstanbul, based on quotated random sampling method and 402 of them found acceptable in the frame work \%95 interval reliability. In tte research, for the Brand Trust Delgado- Ballester's likert type scale (2004, p. 579), for the Brand Loayalty Özdemir and Koçak's (2012) likert type scale and for the Brand Preference Chang ve Liu's Likert type scales were used.

\section{Finding and Discussions}

The results of the reliability and factor analysis is shown Table 1.

Table 1 Reliability and Factor Analysis Results

\begin{tabular}{|l|c|c|c|c|c|c|}
\hline & $\begin{array}{c}\text { Realiability } \\
\text { Analysis }\end{array}$ & \multicolumn{5}{|c|}{ Exploratory Factor Analysis } \\
\hline Scales & $\begin{array}{c}\text { Cronbach } \\
\text { alpha }\end{array}$ & KMO & $\begin{array}{c}\text { Barlett } \\
\text { Sigma }\end{array}$ & $\begin{array}{c}\text { Explanined } \\
\text { Total Variance } \\
\%\end{array}$ & $\begin{array}{c}\text { Number of } \\
\text { Questions }\end{array}$ & $\begin{array}{c}\text { Omitted } \\
\text { Quastions }\end{array}$ \\
\hline Brand Trust & 89,7 & 0,81 & 0,00 & 76,34 & 4 & - \\
\hline Brand Loyalty & 92,1 & 0,88 & 0,00 & 76,2 & 5 & - \\
\hline $\begin{array}{l}\text { Brand } \\
\text { Preference }\end{array}$ & 91,2 & 0,84 & 0,00 & 79,1 & 4 & - \\
\hline
\end{tabular}

The result of regression analysis between Brand Trust and Brand Loyalty is shown Table 2. 
Table 2 Brand Loyalty and Brand Trust Regression Model Summary

\begin{tabular}{|c|c|c|c|c|c|c|}
\hline \multicolumn{7}{|c|}{ Dependent Variable: Marka Sadakati } \\
\hline $\begin{array}{c}\text { Independent } \\
\text { Variable } \\
\end{array}$ & $\mathrm{F}$ & $\mathrm{P}$ & $\begin{array}{c}\mathrm{B} \\
\text { co-efficent }\end{array}$ & S.E & $\mathrm{T}$ & VIF \\
\hline (Constant) & \multirow[b]{2}{*}{1567,81} & \multirow[b]{2}{*}{0,00} & 0,18 & 0,07 & 2,39 & \multirow[b]{2}{*}{1,0} \\
\hline Marka Güveni & & & 92 & 0,2 & 35,59 & \\
\hline $\mathbf{R}^{2}=, 89$ & ADjuste & $2=, 79$ & & $\begin{array}{l}\text { Durbi } \\
1,64 \\
\end{array}$ & tson co & \\
\hline
\end{tabular}

The related regression equation is Brand Loyalty $=0,18+0,93 *$ Brand Trust; therefore tehere is a postive and good association between Brand Loyalty and Brand Trust. Meaning that if 0,93 unit Brand Trust increase by constant 0,14 unit than on Brand Loyalty one unit positively increase. The result of regression analysis between Brand Preference and Brand Trust is shown Table 3.

Table 3 Brand Preference and Brand Trust Regression Model Summary

\begin{tabular}{|l|c|c|c|c|c|c|}
\hline Dependent Variable: Marka Tercihi \\
\hline $\begin{array}{c}\text { Independent } \\
\text { Variable }\end{array}$ & $\mathrm{F}$ & $\mathrm{P}$ & $\begin{array}{c}\mathrm{B} \\
\text { co-efficent }\end{array}$ & $\mathrm{SE}$ & $\mathrm{T}$ & $\mathrm{VIF}$ \\
\hline Mark Güveni & 5328,70 & 0,00 &, 99 & 0,2 & 35,59 & 1,0 \\
\hline $\mathbf{R}^{2}=, 93$ & \multicolumn{2}{l|}{ Adjusted $\mathbf{R}^{2}=, 93$} \\
\hline
\end{tabular}

The related regression equation is Brand Preference 0,99*Brand Trust; therefore tehereforee is a postive and good association between Brand Preference and Brand Trust.

Meaning that if 0,99 unit Brand Loyalty increase than on Brand Preference postively one unit increase. The result of regression analysis between Brand Preference and Brand Loyalty is shown Table 4.

Table 4 Brand Loyalty and Brand Preference Regression Model Summary

\begin{tabular}{|c|c|c|c|c|c|c|}
\hline \multicolumn{7}{|c|}{ Dependent Variable: Marka Sadakati } \\
\hline $\begin{array}{c}\text { Independet } \\
\text { Variable }\end{array}$ & $\mathrm{F}$ & $\mathrm{P}$ & $\begin{array}{c}\text { B } \\
\text { co-efficent }\end{array}$ & SE & $\mathrm{T}$ & VIF \\
\hline (Cosntant) & \multirow[b]{2}{*}{1101,14} & \multirow[b]{2}{*}{0,00} & 0,43 & 0,095 & 5,13 & \multirow[b]{2}{*}{1,0} \\
\hline Marka Tercihi & & & ,86 & 0,026 & 33,18 & \\
\hline $\mathbf{R}^{2}=, 73$ & \multicolumn{3}{|c|}{ Adjsuted $\mathbf{R}^{2}=, 73$} & \multicolumn{3}{|c|}{ Durbin-Watson co-efficent $=1,89$} \\
\hline
\end{tabular}

The related regression equation Brand Loyalty and Brand Preference is; Brand Loyalty $=0,43+0,86 *$ Brand Preference; therefore there is a postive and good association between Brand Loyalty and Brand Preference. Meaning that if 0,86 unit Brand Preference incerease by 0,43 constant unit than one unit Brand Loyalty positively increase.

When we evaluate the scales according to the percentage points of consumers, brand trust was realized as per cent value $(61 \%)$, brand loyalty $(62 \%)$, brand preference $(61 \%)$. These values are estimated to be slightly above the average and firms need to improve these components in terms of all three brand components. The success rankings of the existing brands in all of the brand scales have emerged as Fabel Castell (1.), Bic (2.) and Fatih (3.) brands. 
In the regression analysis, it is determined that brand trust is rassociaited with the brand loyalty in a significant and positive way and the relevant $\mathrm{H}_{1}$ hypothesis is accepted. Accordingly, the increase in per-unit brand confidence positively increases brand loyalty by 0,18 units and 0,93 units in favor of fixed support. Similarly, theassociaition between brand trust and brand preference is determined in a siginificant and positive way, and the relevant $\mathrm{H}_{2}$ hypothes is accepted. Accordingly, the increase in per-unit brand confidence increases the brand preference by 0,99 units positively. Likewise, the association between brand preference and brand loyalty is determined in a significant and positive way, and the relevant $\mathrm{H}_{3}$ hypothesis is accepted. Accordingly, the increase in per unit brand preference increases brand loyalty positively by 0,86 units in addition to the constant increase of 0,43. As in previous studies, it has been revealed that brand trust in this study supports brand loyalty in a positive way at high level. At the same time, trust in the brand also influenced the brand preference positively. For this reason consumers should consider that brand trust is an important factor in choosing the brand we are offering, and work towards this should be improved. In this sense, we can say that brand trust is a common and important component that supports brand loyalty, and also favorably towards brand preference. The mediating role between brand trust and brand loyalty of the brand preference has not been tested in the study but it is predicted from the results obtained. The work is done in the stationery pen sector. It is also useful to compare the results of similar studies in other sectors.

As a result, this study found that brand trust affects brand preference and brand loyalty at a high level in the significant and positive direction, and that the brand preference affects the brand loyalty at a significant and positive high level. This study will provide an add-value for brand managers and literature support in terms of brand trust, brand loyalty and brand preference associaitions in brand management. However, there are many other factors that affect brand trust, brand loyalty and brand preference such as brand awareness, brand identity, brand experience, consumer sociological, psychological factors. For this reason, it is recommended to compare the findings of this study by making studies about the other factors that can affect the brand management. The study was made in the sector of stationery paint pencil and it is beneficial to compare the results of studies related to brand trust, brand loyalty and brand preference in other sectors. 